only criteria. The clear persistence of the symptoms suggests that functional hypoglycaemia is a clinical condition. The general failure to show chemical hypoglycaemia, however, questions the use of the term functional hypoglycaemia and suggests a different explanation for the phenomenon. The glycaemic threshold for onset of hypoglycaemic symptoms and release of counterregulatory hormones might be higher than in normal subjects. Further studies should test this hypothesis.

In conclusion, hypoglycaemic symptoms seem to be persistent in subjects with functional hypoglycaemia but are not related to chemical hypoglycaemia. This suggests the existence of a clinical condition but questions whether the commonly used term for this condition is appropriate.

1 Yager J, Young RT. Non-hypoglycemia is an epidemic condition. $N$ kingl $\mathcal{f}$ Med 1974;291:907-8.

2 Betteridge DJ. Reactive hypoglycaemia. Br.Med 7 1987;295:286-7.
Gastineau CF. Is reactive hypoglycemia a clinical entity? Mayo C/in I'rou 1983:58:545-9.

Hogan MJ, Service FJ, Sharbrough RW, Gerich JE Oral glucose tolerance est compared with a mixed meal in the diagnosis of reactive hypoglycemia. Mavo Clin Proc 1983:58:191-6.

5 American Diabetes Association. Statement on hypoglycemia. Diabetes (iar 1982:5:72-3.

6 Marks V. Functional hypoglycemia: fact or fancy? In: Andreani D, ed. Hypoglycemia Serono Sumposia 1986:38:1-17.

Bernstein RK. Meaningful screening test for reactive hypoglecemia. Diabetes Care 1987:10:792-3.

8 Lev-Ran $A$, Anderson RW. The diagnosis of postprandial hepoglvcemia. Dlabetes 1981;30:996-9.

9 Jung Y, Khurana RC, Corredor DG, et al. Reactive hypoglycemia in women Diabetes 1971;20:428-34.

10 Lefebvre P'J, Andreani D, Marks V, Creutzfeldt W. Statement on "post prandial" or "reactive" hypoglycaemia. Diabetologia 1988;31:68-9.

11 Charles MA, Hofeldt FD, Shackelford A, et al. Comparison of oral glucose tolerance tests and mixed meals in patients with apparent idiopathic postabsorptive hypoglvcemia. Diabetes 1981:30:465-70.

12 Buss RW, Kansal PC, Roddam RF, Pino J, Boshell BR. Mixed meal tolerance test and reactive hypoglycemia. Horm Metabol Res 1982;14:281-3.

13 Crapo PA, Scarlett JA, Kolterman OG, Sanders LR, Hofeldt FD, Olefsky JM. The effects of oral fructose, sucrose, and glucose in subjects with reactive hypoglycemia. Diabetes Care 1982;5:512-7.

Accepted 30 September 1989)

\title{
Single dose cefotaxime plus metronidazole versus three dose cefuroxime plus metronidazole as prophylaxis against wound infection in colorectal surgery: multicentre prospective randomised study
}

\author{
D C Rowe-Jones, A L G Peel, R D Kingston, J F L Shaw, C Teasdale, D S Cole
}

Abstract

Objective-To establish whether a single preoperative dose of cefotaxime plus metronidazole was as effective as a standard three dose regimen of cefuroxime plus metronidazole in preventing wound infection after colorectal surgery.

Design-Prospective randomised allocation to one of two prophylactic antibiotic regimens in a parallel group trial. Group sequential analyses of each 250 patients were performed.

Setting-14 District general and teaching hospitals.

Patients-1018 Adults having colorectal operations were randomised, of whom 943 were evaluated. Demographic features, conditions requiring surgery, and operative procedures were similar in the two groups. Most patients had surgery for carcinoma of the colon or rectum.

Interventions-Group 1 received cefotaxime $1 \mathrm{~g}$ intravenously plus metronidazole $500 \mathrm{mg}$ intravenously preoperatively. Group 2 received cefuroxime $1.5 \mathrm{~g}$ intravenously plus metronidazole $500 \mathrm{mg}$ intravenously preoperatively, followed by cefuroxime $750 \mathrm{mg}$ intravenously plus metronidazole $500 \mathrm{mg}$ intravenously eight hours and 16 hours postoperatively.

Main outcome measures-Development of surgical wound infection (as evidenced by the presence of pus), death, or discharge from hospital.

Results - Wound condition was scored on a five point scale on alternate days until discharge or for up to 20 days postoperatively. Wound infection rates were: group $1,32 / 453(7 \cdot 1 \% ; 95 \%$ confidence interval $4.7 \%$ to $9.4 \%)$; group $2,33 / 454(7 \cdot 3 \%$; $95 \%$ confidence interval $4.9 \%$ to $9 \cdot 6 \%$ ). Death rates (group 1: $26 / 470(5 \cdot 5 \%)$; group 2: $31 / 471(6 \cdot 6 \%)$ ), the incidence of postoperative complications, the median duration of hospital stay (12 days), and antibiotic tolerance were all similar in the two groups. Pooled data from groups 1 and 2 showed that wound infections were more frequent when minor faecal contamination had occurred at operation and when the duration of operation exceeded 90 minutes ( $>90 \mathrm{~min} 11.2 \%$ of cases; $<90 \mathrm{~min} 4.8 \%$ ) and were associated with an extended hospital stay.

Conclusions-A single preoperative dose of cefotaxime plus metronidazole is as efficacious as a three dose regimen of cefuroxime plus metronidazole in preventing wound infection after colorectal surgery and has practical advantages in eliminating the need for postoperative antibiotics.

\section{Introduction}

The use of antibiotics for prophylaxis against wound infection is well established in patients having operations on the gastrointestinal tract, particularly the large bowel, where the risk of infection from faecal micro-organisms is high. ${ }^{2}$ Despite acceptance of antibiotic prophylaxis in principle there is wide variation in the composition and duration of the antibiotic regimens employed. ${ }^{34}$ The ideal prophylactic regimen for large bowel surgery would exemplify activity against both aerobic and anaerobic bacteria with a consequent low incidence of wound infection, safety from unwanted drug effects, convenience of delivery, and low cost. A single preoperative dose of prophylactic antibiotics shown to be of equal efficacy to a commonly used multiple dose regimen would satisfy these criteria. Though single dose regimens are established for "clean" procedures such as operations on the biliary and upper gastrointestinal tracts, convincing and statistically sound evidence for efficacy is lacking in procedures such as colorectal surgery, which have a potentially much greater degree of contamination.

Several studies have investigated the role of single dose preoperative systemic antibiotics alone or compared with multiple dose regimens in patients having colorectal surgical procedures. The single dose regimens tested have included a ureidopenicillin $\left(\operatorname{mezlocillin}^{6}\right)$, cephalosporins (cefuroxime, ${ }^{7-9}$ cefo- 
$\operatorname{tetan}^{10}$ (K P Bouter et al, abstracts of 28th interscience conference on antimicrobial agents and chemotherapy, Los Angeles, 23-26 October 1988, p 324), ceftriaxone, ${ }^{1112}$ latamoxef, ${ }^{13}$ cefmetazole $\left.^{14}\right)$, and a penicillin- $\beta$-lactamase inhibitor combination agent. ${ }^{15}$ In many of these studies equivalent efficacy in terms of wound infection rates has been claimed. But comparative trials which are large enough to avoid a type II error (the possibility of not detecting a significant difference in infection rates when one exists) are uncommon, and the claims based on fairly small numbers of patients are subject to criticism for having low statistical power. ${ }^{16}$ It is difficult for a single centre trial to accumulate enough patients to overcome this problem. Multicentre studies adhering to a common protocol are preferable when antibiotic regimens with similar efficacy are being compared.

In this study a single preoperative dose of the third generation cephalosporin cefotaxime combined with metronidazole was evaluated as prophylaxis against wound infection in patients having all types of colorectal surgery at 14 hospitals. A randomised, prospective, parallel group comparison was made with a three dose regimen of the second generation cephalosporin cefuroxime, also combined with metronidazole. The comparator regimen was chosen on the basis of evidence from market research that this regimen is in frequent usage in British surgical practice, substantiated by recent trials in which the same multidose regimen was employed. ${ }^{61718}$

\section{Patients and methods}

Inclusion and exclusion of criteria-Patients aged 16 and over admitted for all types of colorectal surgery (elective or emergency) to each of the 14 participating hospitals were considered for the trial. Patients were not included if they had a history of allergy to penicillins or cephalosporins, had received antibiotics within 48 hours before surgery, or had evidence of an existing infection before or at operation. After randomisation and entry into the trial any patients who did not have the large bowel or rectum opened during surgery - for example, those found at operation to have inoperable carcinomas - or who had a procedure such as appendicectomy rather than colorectal surgery were excluded from analysis. Patients who were found at operation to have severe faecal contamination of the peritoneal cavity due to a perforated colon or owing to a surgical mishap required prolonged antibiotic treatment and were therefore withdrawn from the trial. A minor degree of faecal contamination was recorded if present but did not lead to exclusion. Any patient who failed to complete the specified prophylactic regimen or who was given additional antibiotics at the time of surgery was also excluded from analysis. Patients received mechanical bowel preparation only.

Study design - On admission to the trial demographic information and the reason for surgery were recorded. The next consecutive number in the sequence given to each centre was then allocated. Eligible patients were entered at random into one of two treatment groups by opening a sealed envelope containing details of the prophylactic antibiotic regimen to be used. The randomisation list was generated by a computer program which allocated patient numbers to the two treatment groups with a block size of 10 . In centres in which two or more surgeons were participating in the trial these blocks of 10 were maintained intact for each surgeon in an attempt to minimise interoperator variation.

Trial antibiotics-Patients in group 1 received cefotaxime $1 \mathrm{~g}$ plus metronidazole $500 \mathrm{mg}$ by intravenous infusion after induction of anaesthesia and five to 10 minutes before having their peritoneum opened. Patients in group 2 received an initial dose of cefuroxime $1.5 \mathrm{~g}$ plus metronidazole $500 \mathrm{mg}$ by intravenous infusion after induction of anaesthesia and five to 10 minutes before having their peritoneum opened, followed by two further intravenous doses of cefuroxime $750 \mathrm{mg}$ plus metronidazole $500 \mathrm{mg}$ eight hours and 16 hours postoperatively.

Clinical evaluation-At operation the procedure performed and duration of surgery were recorded. Evaluable patients were observed for evidence of local or systemic adverse reactions to the antibiotics in addition to postoperative complications. Surgical wounds were examined and scored on a five point scale on alternate days beginning the day after the operation until discharge from hospital. The observer was unaware of the regimen used, and a wound was considered infected if the abdominal incision discharged pus. Perineal wounds, if present, were not evaluated. Inpatients were monitored until the day of discharge or the 20th day after operation. Any patient who died within 20 days after operation without developing an infection was excluded from analysis of wound infection rates and evaluated for antibiotic tolerance only. If, however, a patient died within 20 days after operation having shown evidence of wound infection he or she was included in analyses of both efficacy and tolerance. Patients were routinely reviewed as outpatients four to eight weeks after operation, when any further clinically important complications were recorded.

Microbiological evaluation-Swabs were taken from patients whose surgical wound drained pus and cultured aerobically and anaerobically. Identification of any organism cultured and testing for sensitivity to cefotaxime and cefuroxime were performed whenever possible.

Sample size and statistical methods-Published studies of colonic surgery in which systemic prophylaxis with cephalosporins was used have shown wound infection rates in the region of $10-15 \% .^{36819}$ We decided to test for a $5 \%$ difference in infection rates between the two treatment groups with a $90 \%$ statistical power and 5\% level of significance by using a group sequential analysis with predetermined inspection intervals. ${ }^{20}$ At the outset a triangular plot was constructed in which stopping boundaries for the trial were laid down. Interim analyses of wound infection rates were planned at inspection intervals of each 250 patients completing the trial-that is, after 250 , $500,750,1000$, and so on. At each point coordinates were to be plotted on the graph. The first occasion on which the coordinates fell outside the predefined triangular area became the valid stopping point for the trial. Wound infection rates were compared by $\chi^{2}$ test with Yates's correction. Other results were analysed by $\chi^{2}$ tests, except for ordered categorical data, which were analysed by logistic regression techniques. ${ }^{21}$

Ethics-Written agreement to the study protocol was obtained from the ethics committee at each participating hospital before the trial. Informed consent from patients was sought either verbally or in writing.

\section{Results}

\section{PATIENT POPULATION}

Over the two years ending in January 1989 (when the trial was stopped on the basis of the fourth group sequential analysis) 1018 patients had been admitted to the study at the 14 participating centres. Of these patients, $75(7 \cdot 4 \%)$, equally divided between the two groups, were excluded. Thirty seven had severe faecal contamination or peritonitis at operation; in 30 the surgical procedure did not include opening the colon or rectum; in seven an incomplete, incorrect, or 


\begin{tabular}{|c|c|c|c|c|c|}
\hline \multirow[b]{2}{*}{ Treatment group } & \multirow{2}{*}{$\begin{array}{c}\text { No } \\
\text { of } \\
\text { patients }\end{array}$} & \multirow{2}{*}{$\begin{array}{c}\text { Median age } \\
\text { (years) } \\
\text { (range) }\end{array}$} & \multicolumn{2}{|c|}{ Sex } & \multirow{2}{*}{$\begin{array}{c}\text { Mean } \\
\text { body mass index } \\
\left(\mathrm{kg} / \mathrm{m}^{2}\right)(\mathrm{SD})\end{array}$} \\
\hline & & & M & $\mathrm{F}$ & \\
\hline 1 (Single dose cefotaxime plus metronidazole) & 471 & $67(16-92)[n=470]$ & 224 & 247 & $23 \cdot 9(4 \cdot 2)[n=338]$ \\
\hline 2 (Three dose cefuroxime plus metronidazole) & 472 & $69(17-89)[n=469]$ & 234 & 238 & $23.4(3.9)[n=329]$ \\
\hline Total & 943 & $68(16-92)[n=939]$ & 458 & 485 & $23 \cdot 7(4 \cdot 0)[n=667]$ \\
\hline
\end{tabular}

anterior resection, sigmoid colectomy, and abdominoperineal resection.

\section{WOUND INFECTION}

Interim analyses of 250,514 , and 776 patients had shown wound infection rates of $6-12 \%$. Inspection at the third analysis point produced coordinates very close to the stopping boundary of the triangular test. The fourth analysis was carried out when just over 900 evaluable records were available to the study monitor, and patient entry was terminated on calculation of coordinates which lay beyond the stopping boundary.

On stopping the trial the incidence of wound and one patient was under age. The remaining 943 patients were evaluable for comparison of mortality, complication rates, and tolerance of the antibiotics. Excluded from evaluation of wound infection rates were a further 36 patients $(3 \cdot 5 \%)$, equally divided between the two groups, who died within 20 days of surgery without having shown evidence of wound infection. A total of 907 patients were therefore compared for wound infection rates in the two treatment groups.

Demographic features of the 943 evaluable patients at entry to the trial are shown in table I. The two treatment groups were closely matched for age and sex distribution. Mean body mass index (weight $(\mathrm{kg}) /$ height $^{2}\left(\mathrm{~m}^{2}\right)$ ) was also similar in the two groups, but missing data (commonly height) restricted the numbers of patients for whom this statistic could be calculated.

\section{SURGERY}

Table II lists the presenting conditions in the 943 patients. Most patients entered in the study had elective colorectal surgery, though 70 were classified on entry as having an obstructed bowel and were managed as emergency cases. The commonest presenting condition was carcinoma of the colon or rectum. Mechanical bowel preparation (enemas and washouts) was recorded for $804(85 \cdot 3 \%)$ patients. A similar distribution of operative procedures was performed in each treatment group (table III). The commonest procedures were right hemicolectomy,

TABLE II-Conditions requiring surgery in 943 evaluable patients randomised to receive single dose cefotaxime plus metronidazole (group 1) or three dose cefuroxime plus metronidazole (group 2)

\begin{tabular}{lrrrr}
\hline & \multirow{2}{*}{$\begin{array}{c}\text { No }(\%) \\
\text { of }\end{array}$} & \multicolumn{2}{c}{ Treatment group } \\
\cline { 3 - 5 } pondients & \multicolumn{1}{c}{1} & \multicolumn{1}{c}{2} \\
\hline Carcinoma of colon & $352(37 \cdot 3)$ & 180 & 172 \\
Carcinoma of rectum & 271 & $(28 \cdot 7)$ & 133 & 138 \\
Obstructed bowel & 70 & $(7 \cdot 4)$ & 37 & 33 \\
Diverticular disease & 63 & $(6 \cdot 7)$ & 31 & 32 \\
Inflammatory bowel disease & 62 & $(6 \cdot 6)$ & 31 & 31 \\
Bowel stricture (benign) & 9 & $(1 \cdot 0)$ & 5 & 4 \\
Ischaemic bowel disease & 7 & $(0 \cdot 7)$ & 2 & 5 \\
Other & $109(11 \cdot 6)$ & 52 & 57 \\
\hline Total & $943(100 \cdot 0)$ & 471 & 472
\end{tabular}

TABLE III -Surgical procedures performed in 943 evaluable patients randomised to receive single dose cefotaxime plus metronidazole (group 1) or three dose cefuroxime plus metronidazole (group 2)

\begin{tabular}{lrrrr}
\hline & \multirow{2}{*}{$\begin{array}{c}\text { No (\%) } \\
\text { of }\end{array}$} & \multicolumn{2}{c}{ Treatment group } \\
\cline { 3 - 5 } Surgical procedure & patients & 1 & 2 \\
\hline Right hemicolectomy & 184 & $(19 \cdot 5)$ & 90 & 94 \\
Left hemicolectomy & 49 & $(5 \cdot 2)$ & 25 & 24 \\
Transverse colectomy & 27 & $(2 \cdot 9)$ & 14 & 13 \\
Sigmoid colectomy & 133 & $(14 \cdot 1)$ & 64 & 69 \\
Anterior resection & 155 & $(16 \cdot 4)$ & 73 & 82 \\
Hartmann's procedure & 62 & $(6 \cdot 6)$ & 28 & 34 \\
Abdominoperineal resection & 132 & $(14 \cdot 0)$ & 73 & 59 \\
Total colectomy with anastomosis & 16 & $(1 \cdot 7)$ & 9 & 7 \\
Total colectomy without anastomosis & 2 & $(0 \cdot 2)$ & 1 & 1 \\
Panproctocolectomy & 17 & $(1 \cdot 8)$ & 7 & 10 \\
Colostomy closure & 46 & $(4 \cdot 9)$ & 25 & 21 \\
Colonic reanastomosis & 33 & $(3 \cdot 5)$ & 15 & 18 \\
Other & 87 & $(9 \cdot 2)$ & 47 & 40 \\
\hline Total & $943(100 \cdot 0)$ & 471 & 472 \\
\hline
\end{tabular}
(table IV). Infection rates of just over $7 \%$ were recorded, irrespective of which prophylactic regimen had been employed. The difference was not significant by $\chi^{2}$ test with Yates's correction $\left(\chi^{2}<0.001 ; \mathrm{p}>0.95\right)$. The $95 \%$ confidence intervals for wound infection rates were: group $1,4 \cdot 7 \%$ to $9 \cdot 4 \%$; group $2,4 \cdot 9 \%$ to $9 \cdot 6 \%$.

TABLE IV-Incidence of wound infection among 907 evaluable patients

\begin{tabular}{lcc}
\hline Treatment group & $\begin{array}{c}\text { No of } \\
\text { evaluable } \\
\text { patients in } \\
\text { each group }\end{array}$ & $\begin{array}{c}\text { No }(\%) \\
\text { with } \\
\text { wound } \\
\text { infection }\end{array}$ \\
\hline 1(Single dose cefotaxime plus metronidazole) & 453 & $32(7 \cdot 1)$ \\
2(Three dose cefuroxime plus metronidazole) & 454 & $33(7 \cdot 3)$ \\
\hline Total & 907 & $65(7 \cdot 2)$ \\
\hline
\end{tabular}

$\gamma^{2}<0.001 ; p>0.95$.

Microbiological culture of wound swabs from the 65 patients with infected wounds yielded organisms in 52 cases, including 10 in which mixed intestinal flora were grown rather than single species. The organisms cultured were a mixture of sensitive and resistant isolates to the two trial cephalosporins. There was no evidence for prevalence of a particular organism, nor was anaerobic infection a problem in either group (two isolates in group 1 , six in group 2). Streptococcus faecalis (resistant to both cefotaxime and cefuroxime) was cultured from two patients in group 1 and four in group 2.

\section{DURATION OF HOSPITAL STAY}

There was no difference in length of inpatient stay between the two groups. The median duration of stay was 12 days in both groups.

POSTOPERATIVE COMPLICATIONS OTHER THAN WOUND INFECTION

Almost one third of patients suffered some form of postoperative complication (infective, non-infective, or death). Though there was a higher overall incidence of complications in the multiple dose group (130/470 patients in group 1, 150/471 in group 2, two patients having missing data on complications), this was not significant. Fifty seven patients $(6.0 \%)$ died during inpatient follow up, 26(5.5\%) in group 1 and $31(6 \cdot 6 \%)$ in group 2. Carcinoma, cardiovascular disease, and pulmonary emboli were the most frequent causes of death in both groups. Death was due to sepsis (usually pneumonia) in only seven of the 36 patients excluded from the analysis of wound infection as a result of early postoperative mortality. Three were patients from group 1 and four were from group 2; these patients did not bias the outcome in any way.

When infective complications other than surgical wound infection (abscess, septicaemia, respiratory tract infection, urinary tract infection) were considered there was no evidence that patients in group 2 had a lower incidence of such complications. The total numbers with these complications were 71 of 470 
patients in group 1 and 91 of 471 in group 2. The incidence of urinary tract infection was higher in group 2 (30/470 patients in group 1, 45/471 in group 2). For non-infective complications (which are unlikely to be associated with prophylactic antibiotics) there was also no difference in the incidence between the groups, except that there were more patients with anastomotic leak in group 2 (10 and 23 patients in groups 1 and 2 respectively).

RELATIONS BETWEEN WOUND INFECTION AND SURGICAL PROCEDURES (POOLED DATA FROM GROUPS 1 AND 2)

Minor faecal contamination at operation was associated with a higher incidence of wound infection (40/389 patients; $10 \cdot 3 \%)$ than absence of noticeable faecal contamination $(25 / 517 ; 4 \cdot 8 \%) \quad\left(\chi^{2}=9 \cdot 1\right.$; $\mathrm{p}<0.03)$. There was a slight but non-significant association between wound infection and obesity; patients with body mass index of $>24$ had a wound infection rate of $8.8 \%$ compared with a rate of $6.5 \%$ among those with a body mass index of $<24$.

More prolonged operations resulted in a higher incidence of infection (table V). Logistic regression showed that operations lasting less than and longer than 90 minutes were associated with wound infection rates of $4 \cdot 8 \%$ and $11 \cdot 2 \%$ respectively $\left(\chi^{2}=13 \cdot 15\right.$; $\mathrm{p}<0 \cdot 03)$. There was no significant difference between the treatment groups or in the interaction of treatment with the duration of surgery. Similarly, there was a significant relation between infection rate and length of hospital stay. Logistic regression showed that the incidence of wound infection increased at the same rate for each treatment group-from $2 \cdot 2 \%$ in patients staying less than 15 days to $13.5 \%$ in patients staying 15 days or more $\left(\chi^{2}=33.1 ; \mathrm{p}<0.001\right)$.

When we set aside the few patients with ischaemic bowel disease and bowel stricture (see table VI) it seemed that rectal carcinoma, bowel obstruction, and diverticular disease were associated with higher incidences of wound infection whereas patients with inflammatory bowel disease had a comparatively low incidence of infection. Similarly, certain procedures (Hartmann's procedure, abdominoperineal resection) seemed to carry higher risks of infection (table VII). Left hemicolectomy had a higher infection rate than did right hemicolectomy. The data in tables VI and VII are not amenable to statistical analyses.

\section{ADVERSE EVENTS}

Seven $(0 \cdot 74 \%)$ adverse events were reported among the 943 evaluable patients. In only two of these was a relation between the event and the antibiotic suspected. One patient allocated to receive three dose cefuroxime plus metronidazole suffered a coagulation disorder eight hours postoperatively followed by fatal haemorrhage four hours later. In the cefotaxime plus metronidazole group one patient who had a ring pessary in situ before operation developed perineal and vaginal candidiasis. No case of pseudomembranous colitis was reported in either group.

\section{Discussion}

This study has shown with a high degree of statistical power that a single preoperative dose of cefotaxime plus metronidazole is of equal efficacy to a standard

TABLE $\mathrm{v}-$ Relation between incidence of wound infection and duration of operation among 907 evaluable patients

\begin{tabular}{lccccc}
\hline & \multicolumn{5}{c}{ Duration of operation (min) } \\
\cline { 2 - 5 } & $\leq 60$ & $61-90$ & $91-120$ & $>120$ & Total \\
\hline No of patients & 171 & 396 & 233 & 107 & 907 \\
No (\%) with infected wounds & $8(4 \cdot 7)$ & $19(4 \cdot 8)$ & $26(11 \cdot 2)$ & $12(11 \cdot 2)$ & $65(7 \cdot 2)$ \\
\hline
\end{tabular}

TABLE VI-Relation between primary condition and subsequent incidence of wound infection in 907 evaluable patients

\begin{tabular}{lcc}
\hline Primary condition & $\begin{array}{c}\text { No of } \\
\text { patients }\end{array}$ & $\begin{array}{c}\text { No }(\%) \text { with } \\
\text { infected wounds }\end{array}$ \\
\hline Carcinoma of colon & 339 & $14(4 \cdot 1)$ \\
Carcinoma of rectum & 261 & $26(10 \cdot 0)$ \\
Obstructed bowel & 63 & $6(9 \cdot 5)$ \\
Diverticular disease & 63 & $10(15 \cdot 9)$ \\
Inflammatory bowel disease & 61 & $2(3 \cdot 3)$ \\
Bowel stricture (benign) & 9 & $1(11 \cdot 1)$ \\
Ischaemic bowel disease & 7 & $1(14 \cdot 3)$ \\
Other & 104 & $5(4 \cdot 8)$ \\
\hline Total & 907 & $65(7 \cdot 2)$ \\
\hline
\end{tabular}

TABLE VII-Relation between surgical procedure and incidence of subsequent wound infection in 907 evaluable patients

\begin{tabular}{lcc}
\hline Surgical procedure & $\begin{array}{c}\text { No of } \\
\text { patients }\end{array}$ & $\begin{array}{c}\text { No }(\%) \text { with } \\
\text { infected wounds }\end{array}$ \\
\hline Right hemicolectomy & 178 & $5(2 \cdot 8)$ \\
Left hemicolectomy & 44 & $3(6 \cdot 8)$ \\
Transverse colectomy & 25 & $2(8 \cdot 0)$ \\
Sigmoid colectomy & 128 & $7(5 \cdot 5)$ \\
Anterior resection & 151 & $12(7 \cdot 9)$ \\
Hartmann's procedure & 59 & $12(20 \cdot 3)$ \\
Abdominoperineal resection & 127 & $12(9 \cdot 4)$ \\
Total colectomy with anastomosis & 15 & 0 \\
Total colectomy without anastomosis & 2 & 0 \\
Panproctocolectomy & 17 & $2(11 \cdot 8)$ \\
Colostomy closure & 44 & $1(2 \cdot 3)$ \\
Colonic reanastomosis & 33 & $4(12 \cdot 1)$ \\
Other & 84 & $5(6 \cdot 0)$ \\
\hline Total & 907 & $65(7 \cdot 2)$
\end{tabular}

three dose regimen of cefuroxime plus metronidazole in preventing wound infection after colorectal surgery. In designing the protocol we recognised that the "ideal" design would have encompassed random allocation to four rather than two parallel arms - that is, single and multiple dose cefotaxime as well as single and multiple dose cefuroxime. Calculations, however, showed that the numbers of patients likely to be needed to differentiate with adequate statistical power among four regimens of similar efficacy (or to establish that four such groups had equal infection rates) would present problems with recruitment. We therefore restricted the protocol to the two prophylactic regimens of principal interest. Even being able to state with $90 \%$ power that the two regimens selected for the trial were not significantly different in terms of wound infection rate required the large series of patients reported here. The use of group sequential analyses had the advantage of allowing the trial to be terminated at the earliest point when statistically valid conclusions could be drawn, and we recommend this to others considering large studies of this nature.

The conclusion from this study that single dose preoperative prophylaxis is efficacious allows the surgeon to be certain of having given effective prophylaxis immediately after induction of anaesthesia without the need to verify that postoperative antibiotic doses have been given.

Variations in hospital contract prices for antibiotics preclude accurate cost comparisons, but a saving with the single dose regimen may reasonably be assumed.

Wound infection rates were rather lower than had been expected at the outset based on published trials in similar series of patients. ${ }^{6819}$ Plainly the incidence of infection is directly related to the definition used (in this case the presence of pus at the abdominal wound site). Nevertheless, had a stricter definition been used-for example, including both positive bacteriological results and pus - then the rate would have been lower still.

The incidence of possibly drug related adverse events was low in both groups, though one coagulation disorder followed by haemorrhage occurred with cefuroxime plus metronidazole. Coagulation disorders 
which may lead to serious postoperative bleeding are more commonly associated with certain cephalosporins having the $N$-methylthiotetrazole side chain ${ }^{22}$ but have been noted with others - such as cefuroxime-lacking this side chain..$^{23}$

Some investigators have suggested that the pharmacokinetic profile of an antibiotic is important if it is to be given only preoperatively and have advocated the use of antibiotics with prolonged elimination half lives-for example, ceftriaxone," which is not available in Britain. Our results imply that this is not necessary for operations lasting up to 90 minutes. The half lives of both cephalosporins used here are in the order of one to one and a half hours. Cefotaxime, however, undergoes desacetylation to a metabolite, desacetylcefotaxime, which has broad spectrum antibiotic activity and hence prolongs the duration of antibiotic activity of the parent drug. ${ }^{24}$ Nevertheless, for operations which extend beyond 90 minutes our results suggest that a peroperative "topping up" dose may be beneficial (though only 107 of $907(11 \cdot 8 \%)$ operations in this study were of greater than two hours' duration). It is evident that prophylactic postoperative doses of cefuroxime plus metronidazole confer no additional benefit over a single preoperative dose of cefotaxime plus metronidazole.

Interim results of this study were presented as posters at the 28th interscience conference on antimicrobial agents and chemotherapy held in Los Angeles in October 1988 and at the 16th international congress of chemotherapy, Jerusalem, in June 1989.

Other participants at the principal centres were I L Rosenberg and H B Devlin, North Tees General Hospital, Stockton; and E Hoare and P Sykes, Trafford General Hospital, Manchester.

Additional participating centres were Kingston General Hospital (R D Leach, G H Farrington, W J D Bradield, P E $M$ Jarrett, $P$ J Billings); Manchester Royal Infirmary ( $T$ V Taylor); Southmead Hospital, Bristol (D J Leaper, H J O White); Leigh Infirmary (J G Mosley, M C Holbrook); Arrowe Park Hospital, Wirral (M G Greaney, J S Elkington); Central Middlesex Hospital (N Menzies-Gow, J PayneJames); Middlesbrough General Hospital (W M Cooke, W A Corbett, D Clarke); St James's University Hospital, Leeds (T G Brennan, R C Kester, the late G Wilson); Prince Charles Hospital, Merthyr Tydfil (P A Braithwaite).

We thank Mrs C Finan, Sister S Walsh, Mrs J Davies, and Miss $J$ Hannington for valuable help with the trial documentation. We are also grateful to Mr P J Thomas for advising on the group sequential study design, Miss Kathryn Legge for performing the statistical analysis, and Miśs Helen Moore for word processing the manuscript.

1 Eykyn SJ, Jackson BT, Lockhart-Mummery HE, Phillips I. Prophylactic peroperative intravenous metronidazole in elective colorectal surgery. Lancet 1979;ii:761-4.

\section{Stimulating reporting of adverse drug reactions by using a fee}

Department of

Pharmacology and

Therapeutics, Trinity

College Medical School, St

James's Hospital, Dublin 8, Ireland

John Feely, MD, professor Siobhan Moriarty, BSC, pharmacist

Patricia O'Connor, MRCPI, lecturer/registrar

Correspondence to: Professor Feely.
2 Keighley MRB, Arabi Y, Alexander-Wiliams J, Youngs D, Burdon DW. Comparison between systemic and oral antimicrobial prophylaxis in colorectal surgery. Lance 1979;i:894-7.

3 Danziger L, Hassan E. Antimicrobial prophylaxis of gastrointestinal surgical procedures and treatment of intra-abdominal infections. Drug Intell Clin procedures and treatm
Pharm 1987;21:406-16.

4 Fry DE. Antibiotics in surgery. An overview. Am f Surg 1988;155(5A):11-5.

Haddock G, Hansell DT, McArdle CS. Survey of antibiotic prophylaxis in gastrointestinal surgery in Scotland -5 years on. 7 Hosp Infect 1988;11: 286-9.

6 Stubbs RS, Griggs NJ, Kelleher JP, Dickinson IK, Moat N, Rimmer DMD. Single dose mezlocillin versus three dose cefuroxime plus metronidazole for the prophylaxis of wound infection after large bowel surgery. I Hosp Infect 1987;9:285-90.

7 Mittermayer H, Gross C, Brucke P. Single dose cefuroxime/metronidazole versus metronidazole alone in elective colorectal surgery. Am Surg 1984;50: $418-23$

8 Cunliffe WJ, Carr N, Schofield PF. Prophylactic metronidazole with and without cefuroxime in elective colorectal surgery. A prospective randomised double-blind study. I $R$ Coll Surg Edinb 1985;30:123-5.

9 Colizza S, De Fazio S, Addari A, Grande R, Cucchiara G. Short-term prophylaxis with cefuroxime in colorectal surgery for cancer. $\mathcal{F}$ Surg Oncol 1987:35:266-8.

10 Jagelman DG, Fabian TC, Nichols RL, Stone HH, Wilson SE, Zellner SR. Single-dose cefotetan versus multiple-dose cefoxitin as prophylaxis in colorectal surgery. Am f Surg 1988;155(5A):71-6.

11 Burdon DW, Keighley MRB. Ceftriaxone and metronidazole as single-dose prophylaxis in colorectal surgery. $S$ Afr Med f 1987;71(suppl):15-8.

2 Shepherd A, Roberts A, Ambrose NS, Youngs DJ, Burdon DW, Keighley MRB. Ceftriaxone, a long acting cephalosporin, with metronidazole is a more effective combination than gentamicin with metronidazole as single dose prophylaxis in colorectal surgery. In: Ishigami J, ed. Proceedings of 14 th ICC Kyoto 1985. Tokyo: University of Tokyo Press, 1985:2425-6. (Recent Advances in Chemotherapy: antimicrobial section 3.)

13 Kingston RD, Kiff RS, Duthie JS, Walsh S, Spicer A, Jeacock J. A comparison of two prophylactic single-dose intravenous antibiotic regimes in the treatment of patients undergoing elective colorectal surgery in a in the treatment of patients undergoing elective colorectal
district general hospital. $₹ R$ Coll Surg Edinb 1989;34:208-11.

14 DiPiro JT, Welage LS, Levine BA, et al. Single-dose cefmetazole versus multiple dose cefoxitin for prophylaxis in abdominal surgery. I Antimicrob multiple dose cefoxitin for prophy
Chemother 1989;23(suppl D):71-7.

15 Jones RN, Wojeski WV. Single-dose surgical prophylaxis using ticarcillin/ clavulanic acid (Timentin): a prospective, randomised comparison with cefotaxime. Diagn Microbiol Infect Dis 1987;7:219-23.

16 Rowe-Jones DC, Cole DS. Single dose mezlocillin versus three dose cefuroxime plus metronidazole for prophylaxis in large bowel surgery. 7 Hosp Infect 1988;12:131-2.

17 Sutton GLJ, Gartell PC, Karran SJ. An open controlled comparison of imipenem (MK-787/MK-791) vs metronidazole plus cefuroxime in the prevention of infectious morbidity complicating colorectral surgery. In Ishigami J, ed. Proceedings of 14th ICC Kvoto 1985. Tokyo: University of Tokyo Press, 1985:2474-5. (Recent Advances in Chemotherapy: antimicrobial Tokyo Press,

18 Diamond T, Mulholland CK, Hanna WA, Parks TG. A prospective randomised trial to compare triple dose mezlocillin with triple dose cefuroxime plus metronidazole as prophylaxis in colorectal surgery. cefuroxime plus metronid.
J Hosp Infect 1988:12:215-9.

19 Cann KJ, Watkins RM, George C, Payne-James J, Crawfurd E, Rogers TR. A Cann KJ, Watkins RM, George C, Payne-James J, Crawfurd E, Rogers TR. A
trial of mezlocillin versus cefuroxime with or without metronidazole for the prevention of wound sepsis after biliary and gastrointestinal surgery. $\mathcal{J}$ Hosp Infect 1988;12:207-14.

20 Whitehead J, Stratton I. Group sequential clinical trials with triangular continuation regions. Biometrics 1983;39:227-36.

21 Hastings RP, ed. SUGI supplemental library. In: SAS user's guide. Version 5 edition. Cary, NC: SAS Institute, 1986:269-93.

22 Donowitz GR, Mandell GL. Beta-lactam antibiotics. N Engl f Med 1988;318: $490-500$

23 Kingston RD, Duthie J. Serious postoperative bleeding associated with a single intravenous dose of cefuroxime and metronidazole. 7 Hosp Infect 1986;7:100-1.

24 Fuchs PC, Jones RN, Barry AL, Allen SD, Ayers LW, Pfaller M Desacetylcefotaxime - another broad spectrum cephalosporin? f Antimicrob Desacetylcefotaxime - ano
Chemother 1989;23:165-7.

(Accepted 19 October 1989)

\section{John Feely, Siobhan Moriarty, Patricia O’Connor}

Despite its limitations, spontaneous (yellow card) reporting of adverse drug reactions is the most effective surveillance system of drugs in clinical practice. Nevertheless, fewer than $10 \%$ of reactions are usually reported.' ' Because of the use of multiple and potent drugs one would expect reactions to occur more commonly in hospital than the reported $0.05 \% .^{3}$ To enhance the level of reporting we performed two studies: firstly a pharmacist collated reports, and, secondly, we offered a fee for each yellow card received.

\section{Patients, methods, and results}

In a six week survey of 136 beds a pharmacist examined patient records for adverse reactions and collected reports from nurses and prescribers who had been circulated with guidelines on reporting drug side effects. Thirty eight reactions were detected among 706 patients $(5 \cdot 4 \%)$, most $(21)$ from patient records; eight were reported by nurses but only three by prescribers (the rest came from a combination of sources).

We then offered IR£3 to junior doctors for each completed yellow card given to a designated registrar. Within six weeks 150 reports had been received (an incidence of $9 \cdot 7 \%$ ). These included two drug associated deaths (streptokinase anaphylaxis, pentamidine pancreatitis) and 27 serious or life threatening ${ }^{4}$ reactions -for example, bone marrow suppression, arrhythmias, gastrointestinal haemorrhage, warfarin interaction, pseudomembranous colitis, hepatotoxicity, and the 